\title{
On the Controversy About the Presence of Grain Boundary Sliding in Mg AZ31
}

\author{
BOEHLERT Carl1,2,3,a , CHEN Zhe ${ }^{1, b}$, GUTIERREZ-URRUTIA Iván ${ }^{4, c}$, \\ LLORCA Javier ${ }^{2,3, d}$ and PÉREZ-PRADO María Teresa ${ }^{3, e}$
}

\begin{abstract}
Highly-textured, rolled AZ31 sheet material shows a significant drop in the plastic anisotropy ( $\mathrm{r}$-value; $\mathrm{r}=\varepsilon_{\mathrm{w}} / \varepsilon_{\mathrm{t}}$ ) in tension between $25^{\circ} \mathrm{C}$ and $200^{\circ} \mathrm{C}$. This behavior was initially explained as a result of the increased activity of non-basal slip with increased temperature. Other authors suggested, however, that the mechanism responsible for this phenomenon was the activation of grain boundary sliding (GBS). Here, in-situ tensile tests have been carried out in an SEM at various temperatures in order to obtain further evidence of the role of GBS during moderate to high temperature deformation of $\mathrm{Mg}$ alloys, which remains highly controversial.
\end{abstract}

\section{Introduction}

The incidence of grain boundary sliding (GBS) during straining of $\mathrm{Mg}$ alloys is still not well understood. Some authors have reported that GBS has a significant contribution to deformation even at room temperature in fine grained alloys [1], while others have found no evidence of this mechanism at low temperatures in $\mathrm{Mg}$ alloys with a wide range of grain sizes [2]. An increasing contribution of GBS at high temperatures, even in materials with conventional grain sizes, has been inferred by several authors from ex situ experimental data [3-6]. However, again, recent studies [7] have refuted this idea.

The aim of this work is to investigate the role of grain boundary sliding during high temperature deformation of a Mg AZ31 alloy by means of in-situ tests in an scanning electron microscope. Tests were carried out at $150^{\circ} \mathrm{C}$ at constant strain rate $\left(10^{-3} \mathrm{~s}^{-1}\right)$ and at a constant applied stress of $75 \mathrm{MPa}$. The contribution of GBS to deformation will be discussed on the light of microstructural observations at several areas in the surface of the gage length during straining. This work is part of a wider experimental campaign, the results of which have been previously published in [8].

\section{Experimental procedure}

Rolled and annealed $\mathrm{Mg} \mathrm{AZ31}$, in the form of a sheet of $3 \mathrm{~mm}$ thickness, was purchased from Magnesium Elektron. This alloy had a strong basal texture, as is usually the case of $\mathrm{Mg}$ rolled sheets. The grain size of the as-received material is $13 \mu \mathrm{m}$. 
Flat dog-bone tensile coupons with gage dimensions of $3 \mathrm{~mm}$ wide by $2.5 \mathrm{~mm}$ thick by $10 \mathrm{~mm}$ long were electro-discharge machined out of the as-received sheet. The samples were machined with the tensile axis parallel to the rolling (RD) and transverse (TD) directions of the sheets. One surface of the samples was mirror-polished. In-situ tensile tests were performed at a constant displacement rate of $0.004 \mathrm{~mm} / \mathrm{s}$, equivalent to a strain rate of approximately $10^{-3} \mathrm{~s}^{-1}$, and at a constant stress of $75 \mathrm{MPa}$, using a screw-driven tensile stage placed inside a Zeiss (Jena, Germany) EVO MA15 SEM at $150^{\circ} \mathrm{C}$. The temperature was maintained within $5 \mathrm{~K}$ of the target using a constant-voltage power supply to a $6 \mathrm{~mm}$ diameter tungsten-based heater located just below the gage section of the sample. An open-bath, closed-loop chiller was used to circulate distilled water at RT through copper tubes to prevent the tensile stage from overheating. A fine-gage K-type thermocouple was spot-welded to the gage section of each sample. After the sample's gage-section reached the desired temperature, a 30 minute period was given to stabilize the thermal stress prior to testing. Secondary electron (SE) SEM images were taken before loading and at various strains throughout the tensile test (the creep test was not interrupted while taking the SEM images). The pressure in the SEM chamber never exceeded $4 \times 10^{-6}$ torr, and therefore oxidation did not detrimentally affect the SEM imaging. The crosshead displacement of the mechanical testing machine was continuously recorded during the test. The strain values were estimated from the displacement measurements taking into account the gage length of the samples. Further details of this apparatus and testing technique can be found elsewhere [8]. The creep test was unloaded after $50 \mathrm{~h}$.

\section{Results and discussion}

Figure 1a illustrates the stress-strain curves corresponding to the tests performed at constant strain rate $\left(10^{-3} \mathrm{~s}^{-1}\right)$ at $150^{\circ} \mathrm{C}$ along the rolling (RD) and transverse (TD) directions. The stress drops are caused by test interruptions for in-situ microstructural examination. Due to the symmetry of the basal fiber texture of the as-received AZ31 alloy, the mechanical behavior of this material along the two testing directions is isotropic and thus the microstructural evolution with strain will be investigated in the longitudinal test (tensile axis parallel to RD). Figure $1 \mathrm{~b}$ shows the creep curve (displacement vs. time) corresponding to the creep tests at a constant stress of $75 \mathrm{MPa}$ and $150^{\circ} \mathrm{C}$. Again, longitudinal and transverse tests rendered very similar results. Here, due to the slow strain rate involved (the strain rate corresponding to the secondary state is approximately $1.1 \times 10^{-6} \mathrm{~s}^{-1}$ ) it was not necessary to stop the test in order to acquire SEM images of the deforming microstructure.
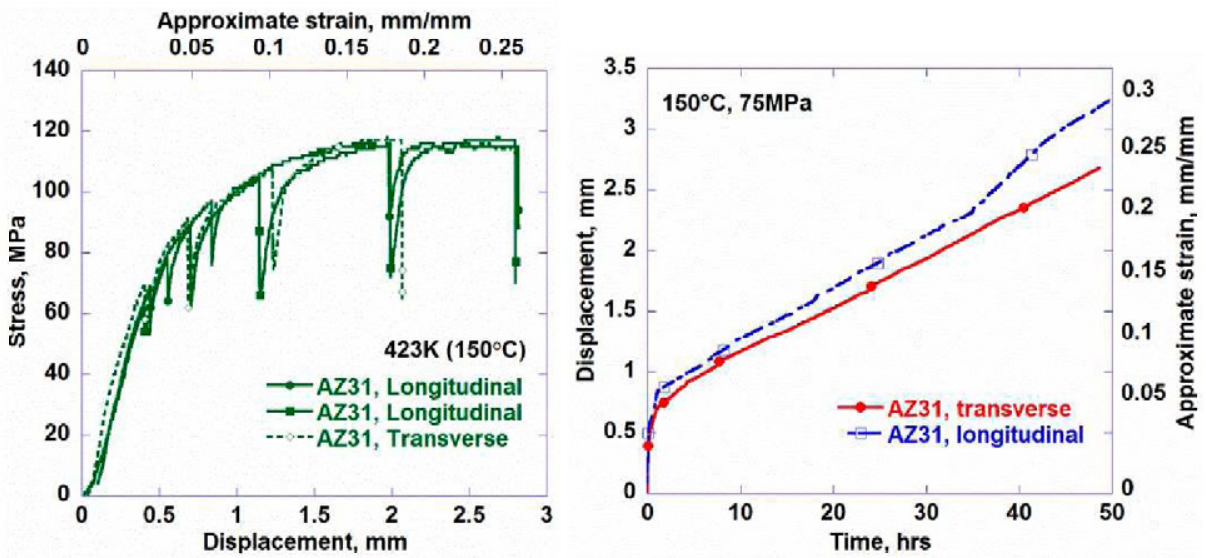

Figure 1. (a) Stress-strain curve corresponding to the tests performed at constant strain rate $\left(10^{-3} \mathrm{~s}^{-1}\right)$ at $150^{\circ} \mathrm{C}$ and (b) displacement vs. time curve corresponding to the creep tests at a constant stress of $75 \mathrm{MPa}$ and $150^{\circ} \mathrm{C}$. 
Figure 2 illustrates two scanning electron micrographs corresponding to the same area of the sample tested at $150^{\circ} \mathrm{C}$ at a constant strain rate of $10^{-3} \mathrm{~s}^{-1}$; the approximate strain values were (a) $1.1 \%$ and (b) $25 \%$. Slip bands were first observed between approximately $4.0-8.5 \%$ strain and their density increased with increasing deformation. In Fig. 2b, taken after a strain of $25 \%$, slip bands can be clearly appreciated and are pointed out with an arrow. The appearance of some grain boundary ledges could be also distinguished after approximately $1.1 \%$ strain (Fig. 2a) and they become more pronounced with increasing strain. In the later stages of deformation some grain boundary cracks were apparent (see white arrow in Fig. 2b). They appeared mostly in boundaries perpendicular to the applied stress (horizontal in Fig. 2). No twinning was observed.

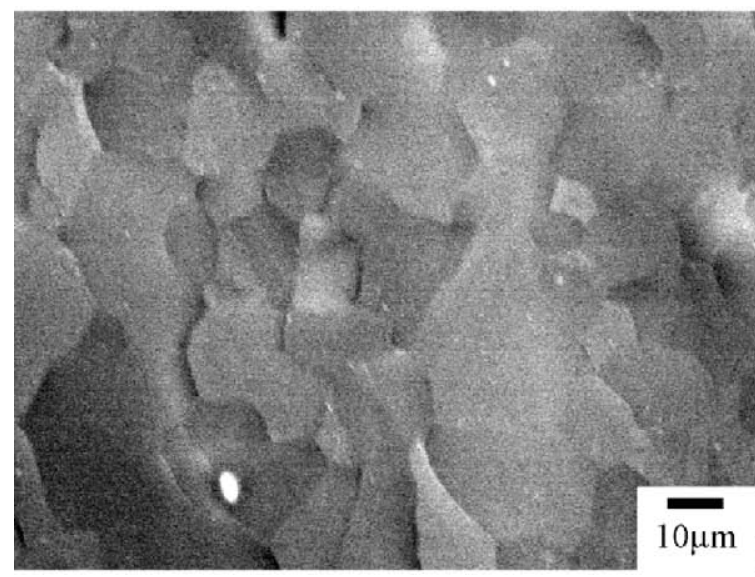

(a) (b)

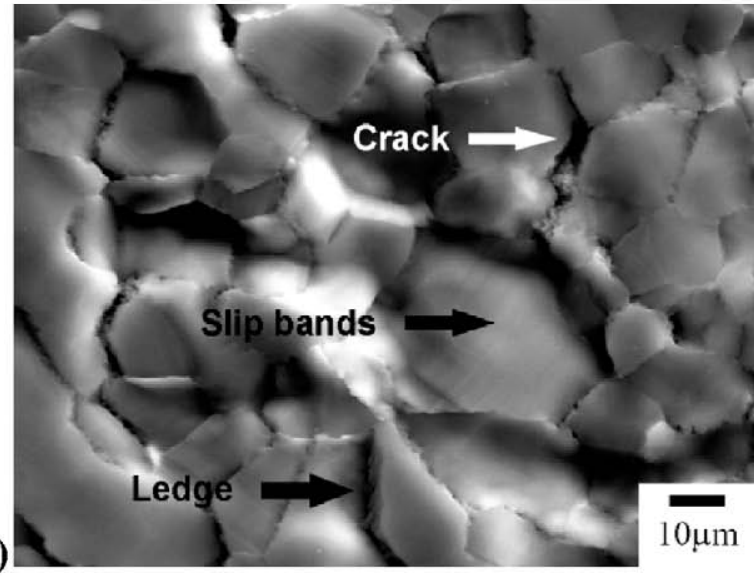

Fig.2. Scanning electron micrographs (secondary electron images) corresponding to the sample tested at $150^{\circ} \mathrm{C}$ at constant strain rate; the approximate strain values were (a) $1.1 \%$ and (b) $25 \%$. The loading axis is parallel to the horizontal direction.

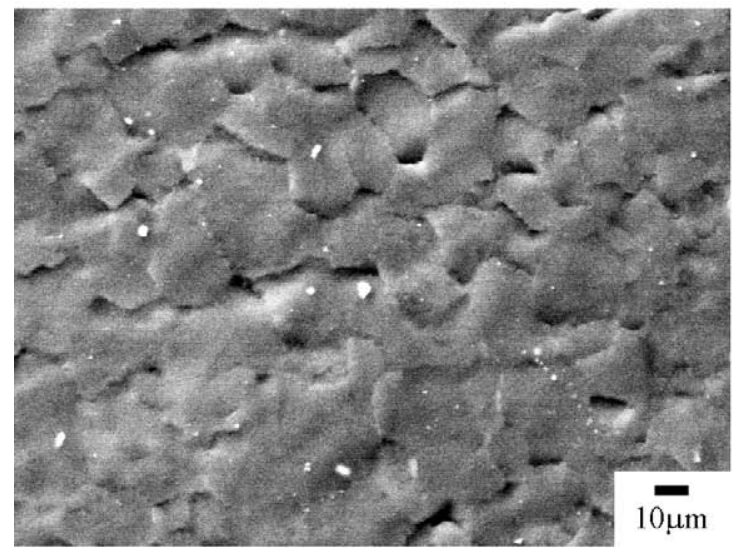

(a) (b)

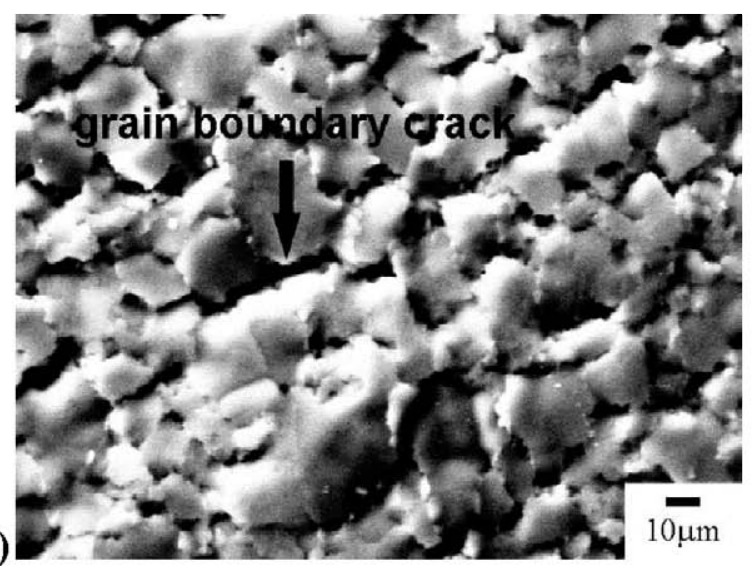

Fig. 3 Scanning electron micrographs (secondary electron images) corresponding to the sample tested at $150^{\circ} \mathrm{C}$ at constant stress $(75 \mathrm{MPa})$. The creep time and approximate strain are (a) $1.1 \mathrm{hrs,}$ $4.4 \%$, and (b) $45.6 \mathrm{hrs}, 22.9 \%$. The loading axis is parallel to the horizontal direction.

As a comparison, Fig. 3 shows two scanning electron micrographs corresponding to the sample tested at $150^{\circ} \mathrm{C}$ at a constant stress of $75 \mathrm{MPa}$. The creep time and approximate strain levels are (a) $1.1 \mathrm{hrs}, 4.4 \%$, and (b) $45.6 \mathrm{hrs}, 22.9 \%$. The strain corresponding to Fig. $3 \mathrm{~b}$ is similar to that of Fig. $2 \mathrm{~b}$. Almost no slip traces were detected under creep conditions. However, a large fraction of the boundaries were observed to serve as crack nucleation and propagation sites with increasing strain. A comparison of Figs. $2 b$ and $3 b$ reveals that the fraction of grain boundary crack segments is much larger under creep conditions than when testing at a constant strain rate, for similar levels of strain. The incidence of twinning under creep conditions was observed to be negligible. 
Our results suggest that the contribution of grain boundary sliding during deformation at $150^{\circ} \mathrm{C}$ of a Mg AZ31 alloy is very significant under creep conditions (i.e., when straining takes place at very low strain rates) but much less important when deformation is carried out at a constant strain rate of $10^{-3} \mathrm{~s}^{-1}$. The grain boundary ledges observed when testing at constant strain rate may be attributed to strain incompatibilities between neighboring grains and, perhaps, to some minor activation of GBS. These results support the fact that the dramatic decrease in anisotropy observed during tensile deformation of this alloy $[7,9,10]$ is likely due to the enhanced activation of non-basal slip as temperature raises, due to a decrease of the critical resolved shear stress (CRSS) of these slip systems. This is in agreement with previous works by Del Valle et al. [2], and Stanford et al. [7]. GBS could be accommodated by diffusion or by intragranular dislocation movement. The absence of slip lines in the creep tested sample suggests that the former is more likely to operate in the alloy investigated.

\section{Summary}

The present results suggest that grain boundary sliding does not have a significant contribution to deformation in the $\mathrm{Mg} \mathrm{AZ31}$ investigated when it is tested at $150^{\circ} \mathrm{C}$ and at a constant rate of $10^{-3} \mathrm{~s}^{-}$

1 . The observed decrease in anisotropy with increasing temperature reported for this alloy would, thus, be attributed more to the increasing contribution of non-basal slip systems as temperature raises. GBS seems, however, to be the predominant mechanism when this material is tested under creep conditions, in particular at a constant stress of $75 \mathrm{MPa}$. The absence of slip traces during in the creep tested sample suggests that grain boundary sliding is accommodated by diffusion rather than by intragranular dislocation movement.

\section{Acknowledgements}

This work was supported by the National Science Foundation Division of Material Research (Grant No. DMR1107117). CJB acknowledges the support from the Spanish Ministry of Education for his sabbatical period in Madrid (SAB2009-0045). The authors would like to thank the vehicle interior manufacturer, Grupo Antolin Ingeniería, S.A., within the framework of the project MAGNO20081028-CENIT funded by the Spanish Ministry of Science and Innovation.

\section{References}

[1] J. Koike, R. Ohyama, T. Kobayashi, M. Sizuki, K. Maruyama: Mater. Trans. Vol. 44 (2003), p.445.

[2] J.A. Del Valle, O.A. Ruano: Mat. Lett. Vol. 63 (2009), p.1551.

[3] J.A. Del Valle, M.T. Perez-Prado, O.A. Ruano: Metall. Mater. Trans. A Vol. 36 (2005), p.1427.

[4] B. Hutchinson, M.R: Barnett, A. Ghaderi, P. Cizek, I. Sabirov: Int. J. Mat. Res. Vol. 100 (2009), p.556.

[5] N. Munroe, X. Tan. Scr. Mater . Vol. 36 (1997), p.1383.

[6] J.A. Del Valle, O.A. Ruano: Acta Mater. Vol. 55 (2007), p. 455.

[7] N. Stanford, K. Sotoudeh, P.S. Bate: Acta Mater. Vol. 59 (2011), p.4866.

[8] C.J. Boehlert, Z. Chen, I. Gutiérrez-Urrutia, J. Llorca, M. T. Pérez-Prado: Acta mater. Vol. 60 (2012), p. 1889.

[9] S.R. Agnew, O. Duygulu: Int. J. Plast. Vol. 21 (2005), p. 1161.

[10] M.R. Barnett, A. Ghaderi, I. Sabirov, B. Hutchinson: Scr. Mater. Vol. 61 (2009), p.277. 